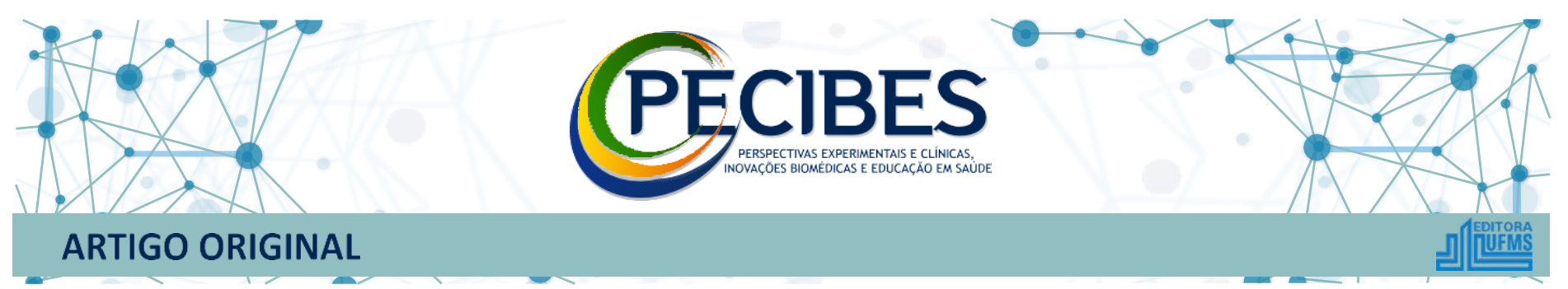

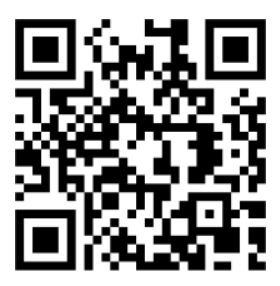

http://www.seer.ufms.br/index.php/p ecibes/index

*Autor correspondente: Jaqueline de Sá Cabral Melo. E-mail do autor: jaquelinedesa_@hotmail.com

Palavras-chave: Ergonomia. E-sport. Fisioterapia no Esport. League of Legends.

Key-words: Ergonomics. Esport. Physiotherapy in Esport. League of Legends.

\section{Análise Ergonômica em Jogadores de E-Sport no âmbito computacional}

\author{
Jaqueline de Sá Cabral Melo ${ }^{1}$, Nelson Kian ${ }^{2}$. \\ ${ }^{1}$ Universidade Católica Bom Bosco - UCDB
}

Ergonomic Analysis in ESport Players in the Computational Scope

\section{Resumo}

Introdução: O crescente número de jogadores dentro do âmbito eletrônico, seja de maneira lúdica ou profissional, nos leva a voltar a atenção para a saúde destes e riscos aos quais estão submetidos. Acredita-se que os e-Sports, como são chamados os esportes eletrônicos, podem oferecer riscos musculoesqueléticos aos que praticam, tendo em vista os constantes movimentos repetitivos (em especial dos punhos e mãos), posturas adotadas e a elevada carga horária em frente ao computador. Objetivo: Analisar de forma individualizada o risco de desenvolvimento de lesões, especialmente de membros superiores, em jogadores de League of Legends. Bem como verificar a postura e biomecânica, traçando, assim, um perfil ergonômico. População e métodos: Em 2020, foram coletados dados ergonômicos de cinco jogadores de League of Legends e comparados com a norma regulamentadora de ergonomia (NR17). Com isso, foram aplicados um auto questionário e os métodos RULA e MOORE GARG, para uma análise mais precisa dos riscos de lesões. Resultados: Foram verificados elevados riscos de lesões em jogadores, decorrentes da alta carga horária frente ao computador, somada ao mau posicionamento e utilização de equipamentos e mobiliários inadequados. As regiões mais prejudicadas em consequência destes fatores, foram punho-mão e a coluna vertebral. Conclusão: Faz-se necessário a propagação de conhecimentos ergonômicos voltada para jogadores de e-Sports, com intuito de orientá-los e prevenir o risco de lesões, proporcionando melhor desempenho e qualidade de vida a estes jogadores.

\section{Abstract}

Introduction: The growing number of players within the electronic environment, whether in a playful or professional manner, leads us to turn our attention to the health of these and risks to which they are subjected. It is believed that e-Sports, as electronic sports are called, can offer musculoskeletal risks to those who practice them, in view of the constant repetitive movements (especially of the fists and hands), postures adopted and the high workload in front of the computer. Objective: To individually analyze the risk of injury development, especially of upper limbs, in League of Legends players. As well as checking posture and biomechanics, thus drawing an ergonomic profile. Population and methods: In 2020, ergonomic data were collected from five League of Legends players and compared with the ergonomics regulatory standard (NR17). With this, a self-questionnaire and the RULA and MOORE GARG methods were applied, for a more precise analysis of the risks of injuries. Results: There was a high risk of injury to players, due to the high workload in front of the computer, in addition to poor positioning and the use of inappropriate equipment and furniture. The most affected regions as a result of these factors were the wrist and the spine. Conclusion: It is necessary to spread ergonomic knowledge aimed at e-Sports players, in order to guide them and prevent the risk of injuries, providing better performance and quality of life for these players. 


\section{Introdução}

Com os avanços tecnológicos e as notáveis transformações que estes acarretam na sociedade, a internet tornou-se uma grande ferramenta de comunicação e entretenimento. Em um contexto histórico, pode-se dizer que foi na década de 70 em que se acentuaram drasticamente os avanços tecnológicos que acarretariam no aparecimento de novos modelos de mídia, dentre as quais destaca-se o computador, incorporando o conceito de interface. Com isso, fortalecem os mercados dos jogos eletrônicos, que por sua vez buscavam incorporar os avanços técnicos dos computadores (Aranha, 2011).

Como forma de acompanhar o avanço da tecnologia, os jogos eletrônicos também passaram por várias transformações ao longo da história. O crescente desenvolvimento no âmbito dos jogos pode ser justificado devido à evolução de hardwares e softwares, o que permitiu expandir a rede dos jogos para diferentes aparelhos, como celular e tablets. Com isto, novas estratégias do mercado para atrair todo tipo de público e gênero também tomaram grandes proporções, o que se estende até os dias atuais (Ribeiro, 2015).

Com os jogos eletrônicos cada vez mais acessíveis, tendo em vista o avanço tecnológico em desenvolvimento, estes foram se tornando cada vez mais convidativos e diversificados. Atualmente, por exemplo, não há mais o conceito de jogos serem "coisas de criança" ou então de serem voltados para o público masculino. Há diferentes manifestações do entretenimento dentro dos jogos, com diferentes propostas, diferentes públicos e premissas.

Em muitos casos, o jogador acaba se envolvendo tanto com a proposta de um jogo, que o intuito de jogar ultrapassa o puro entretenimento. Isso nos remete ao pensamento de que os seres humanos estão constantemente transformando atividades em competições. Charles Darwin explica, em Origem das Espécies, que a competição está relacionada com a luta universal pela existência. Contudo, Darwin ressalta que a necessidade de demonstração de aptidão é o instrumento utilizado pelos seres vivos para que isso lhe traga frutos, seja de forma biológica ou social (De Souza, 2016).

A prova do crescente cenário competitivo dentro do e-Sport, é o aumento constante de número de jogadores que atuam ou sonham em atuar no âmbito profissional, ou seja, que competem por objetivos que vão além do jogo. As competições podem ser desde regionais até a nível mundial, quanto maior a competição, maiores sãos as recompensas dos que saírem vitoriosos. Competições em jogos eletrônicos começaram em 1970 e se estendem até os dias atuais, sejam eles organizados por pessoas ou empresas (Souza, 2017).

Entre os principais jogos da atualidade, destacase o jogo League of Legends. Com popularidade inegável dentro do âmbito do E-Sport, LoL é o MOBA com maior número de jogadores e visualizações em seus torneios no mundo. Multiplayer Online Battle Arena (MOBA), ou "arena de batalha multijogador online" na língua portuguesa, trata-se de uma dinâmica em que duas equipes, cada uma delas formadas por cinco jogadores, se enfrentam em uma arena, com objetivo de destruir o "nexus" inimigo. Cada partida ranqueada dura, em média, 40 minutos (SOUZA, 2017).

Embora muitos jogadores de League of Legends ainda utilizem o jogo apenas como instrumento de entretenimento, novos campeonatos estão sempre surgindo, bem como o número de jogadores engajados em competições. Com isso, muitos jogadores gastam horas em busca do aperfeiçoamento de suas habilidades dentro do jogo e participam de inúmeros torneios realizados, muitos destes com recompensas em dinheiro.

Dentro deste contexto, implica-se verificar se os indivíduos estão ergonomicamente adequados enquanto jogadores, uma vez que muitas horas são gastas em frente ao computador, enquanto realizam movimentos repetitivos com os membros superiores, em especial punho e mão. Ademais, outros fatores biopsicossociais também devem ser considerados quando falamos sobre a saúde destes jogadores, como estilo de vida, cadeira utilizada, postura adotada, entre outros.

A ergonomia é uma importante área onde a Fisioterapia pode contribuir, tendo em vista que esta possuiu papel crucial no que se diz respeito a saúde dos trabalhadores, incluindo jogadores profissionais de esporte eletrônico. Quando bem aplicada, a ergonomia contribui para um trabalho seguro e para a diminuição dos riscos de doenças ocupacionais ligadas ao uso do computador, o que consequentemente melhora o desempenho do trabalho executado e qualidade de vida destes profissionais (Da Sailva, 2017).

Contudo, o objetivo deste trabalho é justamente a realização de uma análise ergonômica, para que dessa forma seja traçado o perfil ergonômico destes jogadores e estudo dos riscos aos quais estes estão submetidos, juntamente com o conhecimento dos fatores associados.

\section{Material e Métodos}

A partir da aprovação para execução da pesquisa de estudo de casos em 2019, CAAE: 26299719.1.0000.5162, e com o aceite do convite feito aos voluntários por meio do TCLE (termo de consentimento livre e esclarecido), foram iniciadas as etapas da pesquisa.

Foram verificados os casos de cinco jogadores de League of Legends (LoL), de idades entre 19 e 21 anos, sendo todo eles brasileiros, do sexo masculino e integrantes do mesmo time competitivo de caráter não profissional. Os questionários foram realizados por meio da plataforma Google Forms no dia 03/06/2020 e tabulados para investigação. Ainda no questionário, foram solicitadas imagens para a realização da análise ergonômica.

Neste questionário, foi possível obter informações de caráter qualitativos e quantitativos, alguns sendo imprescindíveis para a realização dos métodos RULA e Moore Garg. Já as imagens solicitadas, deviam conter o corpo inteiro, no intuito de ser observada a postura adotada e angulação dos membros diante da cadeira e mesa 
utilizada, bem como posicionamento do mouse, teclado e monitor de cada jogador.

Perante as capturas de imagens dos jogadores, foi possível tomar conhecimento do ambiente e estruturas utilizadas durante os jogos por cada um deles. Dessa forma, foi possível realizar uma análise ergonômica e observar as condições em que estes estão inseridos enquanto jogam. Os dados observados foram comparados com os parâmetros ergonomicamente preconizados pela NR17.

A Norma Regulamentadora de Ergonomia, conhecida como NR17, disponibiliza parâmetros que tonam possíveis adaptações das interações entre os seres humanos com outros elementos de um sistema, de forma que otimize o bem-estar e a performance do indivíduo, associando segurança ao conforto (international ergonomics association, 2011).

Como ferramenta de auxílio nesta coleta de dados, foi utilizado o método RULA (Rapid Upper Limb Assessement), um método observacional desenvolvido por Lynn MC Atamney e Nigel Corett em 1993 na universidade de Nottingham. Trata-se de uma ferramenta muito utilizada para a avaliação das posturas adotadas no trabalho. Este método foi realizado com auxílio do programa Kinovea, disponível para computadores, que proporcionou a angulação necessária para análise das fotos solicitadas aos voluntários (Costas, 2016).

RULA é capaz de fornecer suficientes informações para uma análise inicial, possibilitando recomendações rápidas e avaliando de modo geral o indivíduo. A aplicação deste método se dá incialmente pela classificação postural do ombro/braço, posteriormente cotovelo e por fim punho. Seguido, podese avaliar a aplicação de força e repetitividade da ação muscular (Serranheira, 2010).

Ademais, o RULA ainda possibilita avaliação da postura da coluna cervical, tronco e membros inferiores. Os resultados obtidos são combinados e interpretados, evidenciando o nível de risco (score) obtido no final, em uma escala de 1 a 7 , onde o 1 significa "posto de trabalho aceitável" e 7 significa "Posto de trabalho a investigar e alterar urgentemente" (Serranheira, 2010).

Outra ferramenta utilizada na análise foi o Strain Index, popularmente conhecida como MOORE e GARG (devido aos seus criadores). Consiste em um método desenvolvido principalmente para classificar funções e postos de trabalho. É destinado para avaliação de riscos de LER/DORT em extremidades distais dos membros superiores, apropriada para medição ou estimativa de seis variáveis da tarefa, sendo elas a intensidade do esforço, duração do esforço por ciclo de trabalho, número de esforços por minuto, postura da mão/punho, velocidade de trabalho e duração diária da tarefa (Serranheira, 2010).

Para aplicação deste método, é necessário ter informações das atividades que são realizadas pelo profissional, no caso o jogador, e atribuir um nível para cada variável, de acordo com os dados de cada posto de trabalho em relação à exposição de fatores de riscos. $\mathrm{O}$ resultado final se dá pela multiplicação de cada fator de risco observado (Serranheira, 2010).
Assim que coletados, os dados foram tabulados para melhor compreensão dos resultados obtidos e analisados, traçando assim um perfil ergonômico e identificando os principais fatores de risco, relacionandoos com os demais dados obtidos.

\section{Resultados}

Conforme os dados obtidos por meio do questionário, dentre os cinco voluntários que compunham a amostra, quatro são estudantes e um é trabalhador em horário comercial. Todos fazem uso do computador como instrumento para jogar.

$\mathrm{O}$ jogo League of Legends teve seu lançamento inicial em 2009 e se estende até os dias atuais, tendo servidores online em diversos países (Riot Games, 2020). Os voluntários da pesquisa alegam serem jogadores ativos no jogo há, pelo menos, cinco anos. Ademais, quatro dos cinco participantes o jogam todos os dias.Vale ressaltar ainda que, além de LoL, quatro dos cinco voluntários afirmam jogar outros jogos.

A carga horária empregada dentro do jogo é um fator de extrema importância dentro da aplicação dos métodos Moore Garg e RULA, em que o risco é proporcional a quantidade de horas dedicadas na atividade. No método Moore Garg, por exemplo, existe um índice específico para a quantidade de horas.

Para aplicação do método Moore Garg, é necessário ter conhecimento dos movimentos realizados pelos voluntários enquanto jogam. Sabe-se que, apesar não possuir carga, os jogadores estão submetidos a diversos movimentos repetitivos no computador, principalmente do punho e mão ao fazer uso do mouse e teclado.

Por se tratar da mesma atividade, os resultados dos índices se assemelham, conforme mostra a tabela a seguir:

TABELA 1. Resultados da aplicação do método Moore Garg nos voluntários jogadores de e-Sport.

\begin{tabular}{cccccccc}
\hline $\begin{array}{c}\text { JO } \\
\text { G }\end{array}$ & FIT & FDE & FFE & FPMP & FRT & FDT & RISCO \\
\hline 1 & 1,0 & $>80 \%$ & $>20$ & $\begin{array}{c}\text { Não } \\
\text { Neutro } \\
\text { Não }\end{array}$ & $91-100 \%$ & $4-8 \mathrm{hrs}$ & $>7,0$ \\
2 & 1,0 & $>80 \%$ & $>20$ & $\begin{array}{c}\text { Neutro } \\
\text { Não }\end{array}$ & $91-100 \%$ & $4-8 \mathrm{hrs}$ & $>7,0$ \\
3 & 1,0 & $>80 \%$ & $>20$ & $\begin{array}{c}\text { Neutro } \\
\text { Não }\end{array}$ & $91-100 \%$ & $>8 \mathrm{hrs}$ & $>7,0$ \\
5 & 1,0 & $>80 \%$ & $>20$ & $\begin{array}{c}\text { Neutro } \\
\text { Não } \\
\text { Neutro }\end{array}$ & $91-100 \%$ & $4-8 \mathrm{hrs}$ & $>7,0$ \\
\hline
\end{tabular}

Nota: (JOG) Jogador, (FIT) intensidade do esforço realizado, (FDE) duração do esforço, (FFE) frequência do esforço, (FPMP) postura da mão-punho, (FRT) ritmo do trabalho, (FDT) duração do trabalho.

Para essa análise, os jogadores (JOG) foram representados individualmente por meio de números. Como observado na tabela, a intensidade de esforço (FIT) realizado pelos jogadores é mínima, uma vez que não realizam aplicação de força enquanto jogam. Entretanto, observa-se que a duração (FDE) e frequência (FFE) da atividade encontram-se no mais elevado nível em todos os participantes, em decorrência digitação no teclado e movimentação do mouse de forma repetitiva.

É importante mencionar que, durante as partidas, ocasionalmente há situações em que as batalhas se intensificam 
dentro do jogo, o que exige maior agilidade dos jogadores representam a pontuação de cada item e o tamanho de cada para vencê-las. Aliás, ser ágil quanto aos cliques, desvios coluna representa o número de jogadores que obtiveram feitos no mouse e digitações, são qualidades que definem um determinada pontuação.

bom jogador. Portanto, apesar de repetitiva, a frequência dos cliques e digitações não seguem, necessariamente, uma só constante.

A partir das fotos dos jogadores, é possível afirmar que a postura de mão-punho (FPMP) de todos eles se enquadram em "não neutro", sendo este um nível considerado razoável na escala de Moore Garg.

Os jogadores apresentam o ritmo do trabalho (FRT) considerados razoáveis na escala de Moore Garg, uma vez que, mesmo rápido, os jogadores conseguem acompanhar. No entanto, pode ocorrer o que é chamado de "missclick", termo utilizado em jogos para caracterizar situações onde o jogador aperta botões errados, seja por não conseguir acompanhar a demanda de cliques, ou por descuido.

Por fim, o tópico que difere os jogadores 2 e 4 dos demais, é a carga horária empregada no jogo, tida como duração do trabalho (FDT). Três dos voluntários marcaram a opção de que jogam LOL, em média, de 4 a 8 horas diárias, enquanto o restante joga mais do que 8 horas diárias. Com isso, resta a multiplicação de cada índice para a obtenção do resultado final, sendo a fórmula: FITxFDExFFExFPMPxFRTxFDT.

O resultado final do método Moore Garg, alega que todos os voluntários possuem alto risco $(>7,0)$. Considerando que quanto maior a carga horária empregada na execução das atividades maiores são os riscos a ela associados, os jogadores 2 e 4 possuem ainda riscos maiores que os demais.

Desta forma, se verifica com este método que, apesar de não haver aplicação considerável de força, as atividades realizadas por estes jogadores são de alta repetitividade, frequência e ritmo, que associados a má postura da mão-punho e alta duração, acarretam em altos riscos de lesão.

Detectar o risco de lesão é um fator importante para elaborar estratégias de prevenção, pois a avaliação e classificação são algumas das bases para um bom diagnóstico. Todavia, vale lembrar que o método Moore Garg relaciona apenas alguns dos fatores organizacionais e biomecânicos, não considerando os fatores ambientais, que devem ser avaliados de forma separada dentro do contexto ergonômico (SIGNORI, 2004).

Além deste método, foi necessário também a aplicação do método RULA, capaz de gerar scores (pontuações) a partir do posicionamento do indivíduo ao exercer sua atividade. Para medir os ângulos, foi utilizado o programa Kinovea, pelo qual foram obtidas as angulações necessárias para determinar as pontuações.

As fotografias retiradas para análise da angulação devem ocorrer no momento em que o voluntário esteja jogando, de forma que seja capturada a postura habitual na qual este joga.

O método RULA pontua de forma que, quanto menor a pontuação obtida, melhores são as condições de trabalho do indivíduo. Este consiste na análise, por tópicos, de angulações e atividades realizadas, que são passíveis de ajustes para melhor especificação do trabalho observado.

GRÁFICO 1. Gráfico com os resultados do método RULA, com as pontuações obtidas em braço, antebraço e punho pelos voluntários ao jogar League of Legends no computador.

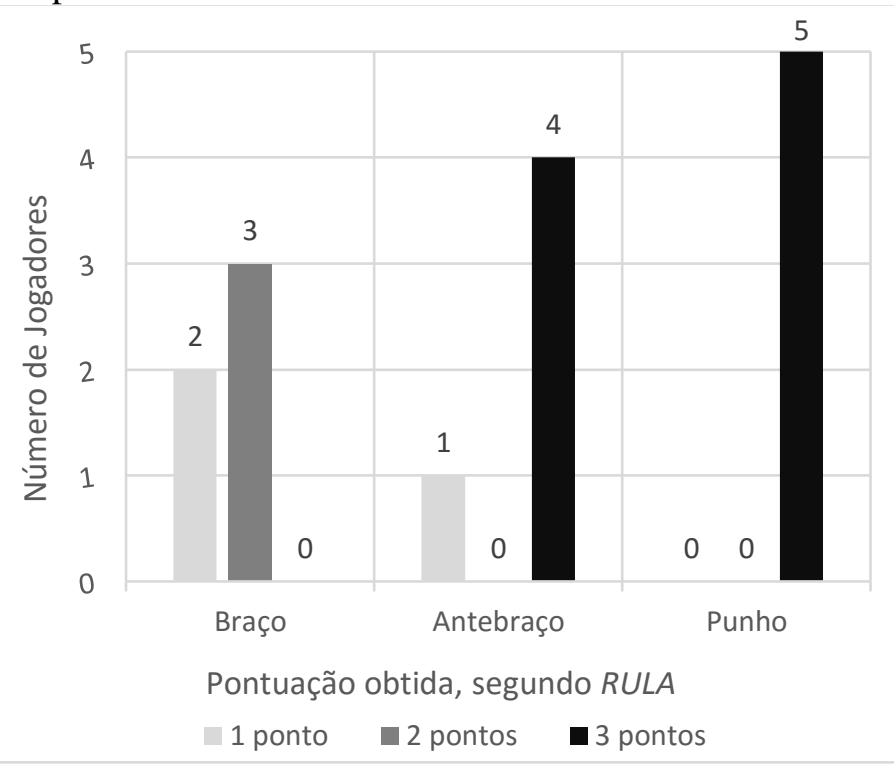

Conforme observado no gráfico, a pontuação do punho foi a mais alta e, também, unanime entre os jogadores. Este fato reflete a consequência do uso do mouse, sendo que este exige movimentação e acionamento repetitivo dos botões em sua superfície, o que torna necessária a manutenção do punho em determinado grau de extensão durante seu uso.

Durante os jogos, o uso do mouse ocorre de maneira constante, o que exige contração isométrica dos músculos extensores do carpo e dedos (SOBOTTA, 1984). Além disso, durante a utilização do mesmo, ocorre leve pronação, somado ao desvio ulnar e radial.

Em segundo lugar destaca-se o antebraço, no qual a pontuação dos jogadores foi, em sua maioria, insatisfatória. Conforme observado nas fotos dos jogadores, a má postura do antebraço está associada à altura irregular de sua cadeira em relação à mesa, bem como a falta de apoio para os cotovelos nas cadeiras. Apenas três dos voluntários possuem cadeira com estes apoios, entretanto, nem todos os usam.

Ocorre que, a altura inadequada, seja da mesa ou cadeira, faz com que todo o segmento corporal se adapte para utilizá-la. Apenas um dos jogadores apresentou mesa e cadeira de altura ideal, porém, a posição que este se encontrava não condizia com o que preconiza a NR17. Este dado nos reflete a ideia de que não basta possuir equipamentos ideais, é necessário saber como usá-los corretamente.

Quanto a pontuação do braço, apesar de ter apresentado o menor dos riscos segundo o gráfico, ainda foi considerada insatisfatória. Isso se dá pela leve abdução do ombro observada em quatro dos cinco voluntários,

Dessa forma, o gráfico a seguir (GRÁFICO 1) representa decorrente da necessidade de ajustar o próprio corpo na o resultado das pontuações obtidas, no qual as cores tentativa de acompanhar a altura do mouse e teclado. Esta 
abdução pode ser ainda acentuada em consequência de movimentações bruscas, principalmente do mouse, enquanto os voluntários jogam.

Apesar do mouse ser considerado um "vilão", a utilização do teclado é igualmente elevada, tendo em vista que neste também ocorre a constante necessidade de desvio ulnar e radial durante o uso das teclas. Ademais, a comunicação é um fator de extrema importância para atingir a vitória em jogos de equipe, como no LoL, o que pode exigir a digitação destes jogadores.

Além dos itens acima citados (braço, antebraço e punho), o método RULA consiste também na análise do pescoço, tronco e pernas dos indivíduos enquanto estes exercem suas atividades. A gráfico a seguir reflete a pontuação obtida pelos voluntários (GRÁFICO 2):

GRAFICO 2 - Gráfico com os resultados do método RULA, com as pontuações obtidas em pescoço, tronco e perna pelos voluntários ao jogar League of Legends no computador.

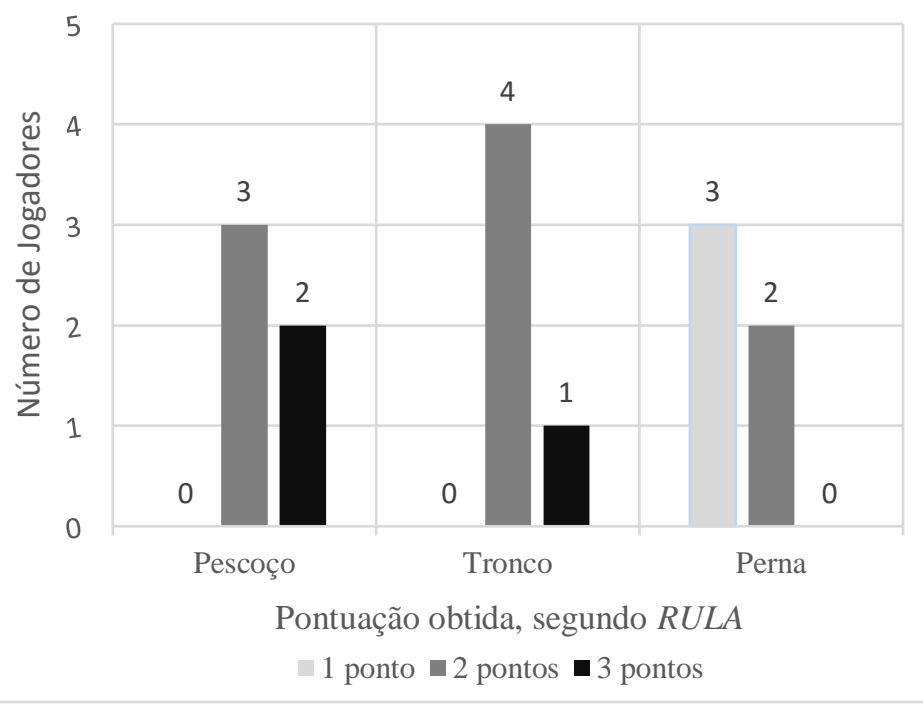

Neste gráfico, é possível observar que a pontuação do pescoço sobressaiu as demais, sendo que dois dos voluntários apresentaram pontuação 3 e o restante a pontuação 2. Este dado é decorrente da visível postura inadequada dos voluntários, sendo que nenhum destes possuem encostos para suas cabeças. A projeção errada da cabeça se dá, também, pelo distanciamento do usuário com monitor e inadequação de altura da cadeira e mesa.

O mesmo ocorre com o tronco, todos os voluntários posicionam o tronco de maneira inadequada, quatro delas por flexão e uma por extensão. Isso se dá novamente devido à altura dos equipamentos e a necessidade que o corpo tem de se adaptar a suas tarefas e buscar pelo conforto (mesmo que de maneira inadequada). Apenas dois dos jogadores mostraram apoiar suas costas na cadeira, bem como, somente três dos voluntários possuem cadeira de altura ajustável.

Quanto a observação da postura de suas pernas, dois dos voluntários possuíam cadeiras altas demais para seus determinados tamanhos. Os restantes dos voluntários apoiam os pés corretamente, sendo que somente um deles usa apoio para os pés.
Contudo, o resultado final do método se dá pelos resultados e cruzamentos das pontuações obtidas, somadas às atividades realizadas e força empregadas. A tabela a seguir (TABELA 2), trata-se do resultado obtido por cada um dos jogadores. Considerando que as pontuações do método variam de 1 (aceitável) a 7 ou maior (necessidade de mudanças urgente).

TABELA 2. Pontuação final dos jogadores no método RULA e suas respectivas interpretações.

\begin{tabular}{ccc}
\hline JOGADOR & PONTUAÇÃO & INTERPRETAÇÃO \\
\hline 1 & 6 & $\begin{array}{c}\text { Necessidade de mudanças na } \\
\text { tarefa. }\end{array}$ \\
3 & 3 & $\begin{array}{c}\text { Podem ser necessárias } \\
\text { mudanças (...). }\end{array}$ \\
4 & 3 & $\begin{array}{c}\text { Necessidade de mudanças na } \\
\text { tarefa. }\end{array}$ \\
5 & 6 & $\begin{array}{c}\text { Podem ser necessárias } \\
\text { mudanças (...). }\end{array}$ \\
& & Necessidade de mudanças na \\
tarefa.
\end{tabular}

Conforme observado na tabela 2 , a maioria dos jogadores apresenta necessidade de mudanças da tarefa. Acredita-se que a adequação dos equipamentos utilizados por estes jogadores, principalmente quanto à altura, somados a orientações, seriam fatores cruciais para melhor adequar as condições dos jogadores ao que preconiza a NR17.

Assim como o método Moore Garg, RULA não considera possíveis fatores ambientais que podem intensificar os riscos, ou então fatores como características individuais de cada indivíduo, como idade, experiência, histórica clínica e estatura. Portanto, também deve ser usado apenas como aliado em uma avaliação ergonômica, e não como fonte de diagnóstico (Sobotta, 1984). Feito estas observações, torna-se importante a análise da presença de dor nos voluntários da pesquisa, obtida por meio do questionário online (GRÁFICO 3).

GRÁFICO 3. Presença de dores relacionadas ao hábito de jogar, segundo voluntários.

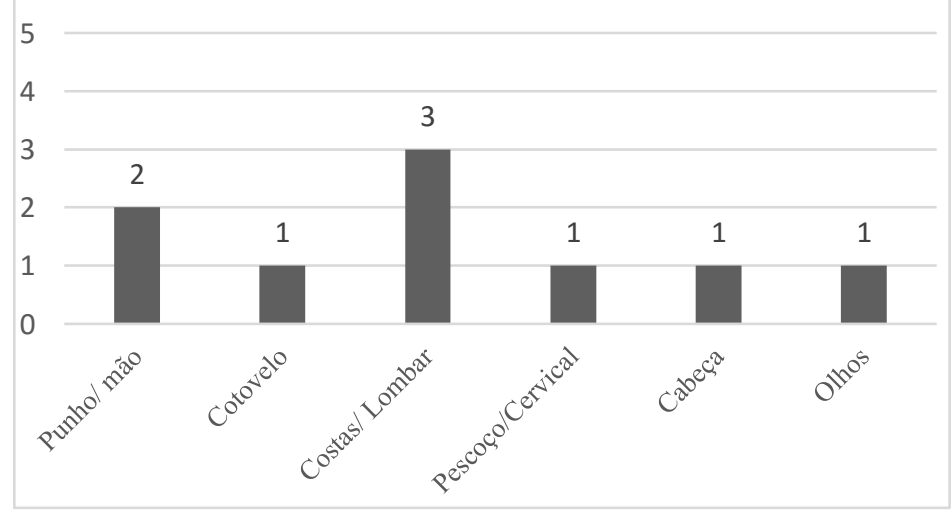

Os voluntários foram instruídos a marcar mais de uma opção, se necessário. Com isso, observa-se que a presença de dores se acentuou principalmente nos itens "punho/mão" e "costas/lombar". Este dado relaciona-se com o que foi analisado nos métodos RULA e Moore 
Garg, e apenas reforçam a ideia de que quanto mais mal posicionados, maiores os riscos.

Certamente, este dado se dá pela má postura observada e relatada nos métodos anteriores, bem como o uso de equipamentos que não condizem com o que preconiza a NR17. Quando questionados sobre a intensidade das dores, os indivíduos relataram serem, em sua grande maioria, leves (2) e moderadas (3), em uma escala de 1 a 5 .

\section{Discussão}

Assim como os profissionais que fazem do computador um instrumento presente no dia-a-dia, os jogadores que League of Legends (LoL) também precisam estar atentos aos riscos aos quais estão submetidos. Dentro deste contexto, pode-se fazer uso da Norma Regulamentadora de Ergonomia (NR-17) como referência de parâmetros ideais para estes usuários.

O Termo Ergonomia deriva-se de duas palavras gregas: Ergos (Trabalho) e Nomos (Leis, Normas e Regras). A International Ergonomics Association define a ergonomia como "a disciplina científica que trata da compreensão das interações entre os seres humanos e outros elementos de um sistema", sendo esta uma profissão que aplica ações e teorias que visam otimizar o bem-estar humano e a performance global dos sistemas.

Estudos advertem que todas as atividades laborais podem causar impactos na saúde do trabalhador, mesmo as que possam parecer seguras, como no caso do uso de computadores (Da Silva, 2017).

De acordo com a NR-17, entre os riscos ergonômicos, relacionados ao uso de computadores observa-se:

\begin{abstract}
“[...] exigência de postura inadequada, utilização de mobiliário impróprio, imposição de ritmos excessivos, trabalho em turno e noturno, jornadas de trabalho prolongadas, monotonia e repetitividade. Além desses riscos, as condições gerais do ambiente de trabalho fazem parte da avaliação ergonômica, aqui incluídos o nível de iluminamento, temperatura, ruído e outros fatores que, após analisados no local, tenham influência no comportamento dos trabalhadores" (Da Silva, 2017).
\end{abstract}

Quando submetidos ao universo dos jogos, muitos jogadores acabam não levando em consideração a própria saúde, pois encontram-se tão focados pela temática que o jogo proporciona, que mal conseguem ter consciência da postura que estão adotando. $\mathrm{O}$ problema surge quando isto ocorre de maneira continua e prolongada, tornando um fator para predisposição de riscos.

Vale mencionar a existência de legislação nacional referente ao que é preconizado para usuários que trabalham com computadores, assegurada pelo DecretoLei n. ${ }^{\circ} 349 / 93$ e Portaria n. ${ }^{\circ}$ 989/93. Estabelecendo prescrições mínimas de segurança e saúde respeitantes ao trabalho com equipamentos dotados de visor.

Ao abrigo do disposto no artigo $5 .^{\circ}$ do Decreto-Lei n. ${ }^{\circ} 349 / 93$, de 1 de Outubro, segundo o Ministro do Emprego e da Segurança Social, manda o Governo instruções sobre o uso dos visores, teclados, mesa ou superfície, cadeiras, princípios de ergonomia aplicados e, também, informações referentes ao ambiente (fatores externos) em que se encontra o trabalhador (Ministério do Emprego e da Segurança Social, 1993).

Entretanto, os jogadores de e-Sport, sobretudo os indivíduos que o jogam apenas como entretenimento, não possuem quaisquer compromissos legais com uma boa ergonomia e estratégias de prevenção de danos. Ocorre que, os indivíduos se submetem a danos tão significantes quanto ao nível de jogadores profissionais e de quem trabalha com computadores, e muitas vezes nem se dão conta disso.

Os resultados mostraram que nenhum dos voluntários se apresenta ergonomicamente correto, pois todos possuem alguma inadequação frente ao uso do computador. Dentro os achados, pescoço, punho e tronco são tópicos onde todos tiveram resultado insatisfatório. Isto se dá, principalmente, em decorrência das alturas irregulares de seus equipamentos, como mesa e cadeira, que reforçam maus hábitos posturais.

Não obstante, os maus hábitos posturais são considerados comuns em indivíduos que passam por longos períodos sentados, uma vez que o corpo começa a relaxar-se e, até mesmo, encurvar-se. Isso deriva de atitudes compensatórias geradas pelo corpo, na busca pelo conforto, e pode ocorrer até mesmo durante o uso dos preceitos ergonômicos, pois ninguém consegue manter a mesma postura por muito tempo (Lianza, 2001).

$\mathrm{O}$ risco maior se dá, pois, problemas posturais gerados no cotidiano a partir da adoção de hábitos errados do ponto de vista biomecânico, são capazes de reduzir a qualidade dos movimentos e provocar lesões no aparelho locomotor, causando modificações fisiológicas e, consequentemente, a dor. (Lianza, 2001; Kisner, 1998).

Por isso, os dados referentes ao mau posicionamento do punho e costas se cruzaram com os dados de maiores prevalências de dores.

Entretanto, estes são riscos que muitos jogadores desconhecem. Por exemplo, os voluntários da pesquisa quando abordados sobre questões ergonômicas, alegaram não saber o que este termo significa. Isto reflete nos resultados obtidos na pesquisa quanto ao posicionamento e hábitos adotados por estes jogadores, uma vez que estes não seriam capazes de corrigir atitudes que não sabem que são erradas.

Apesar de não serem jogadores profissionais, três dos voluntários confessam possuir interesse nesta carreira, o que demanda muito treino. Por isso, jogadores engajados no âmbito competitivo, mesmo que não sejam profissionais, acabam se expondo a elevadas cargas horárias de jogo, na busca pelo aperfeiçoamento.

O que muitos ainda desconhecem, é que o salário de um jogador no ápice de sua carreira, a nível mundial, é consideravelmente alto. Em uma matéria publicada em abril de 2019, revela que a média dos salários na liga, anualmente, é de $300 \mathrm{mil}$ dólares. Este valor foi 
confirmado no palco do evento GamesBeatSummit, 2019, por um comissário da Riot Games, empresa responsável pelo LoL (Porto, 2019).

Isso justifica o interesse e envolvimento de muitos usuários com LoL. E, além da carreira, há outras formas de se adquirir dinheiro no LoL. Por exemplo, no questionário, três dos cinco participantes alegaram já terem adquirido dinheiro por meio do LoL em campeonatos.

Apesar de muitas vezes ser visto como um potencial para vícios (Mena, 2003), os jogos eletrônicos são ricos em benefícios se usados da maneira correta. Estudos indicam que são instrumentos capazes de melhorar a lógica, raciocínio, percepção motora, entre outros benefícios que se estendem até habilidades e valores morais (BATISTA, 2008).

$\mathrm{O}$ problema ocorre quando a alta frequência do uso do computador torna-se um fator de risco. A ausência de equipamentos ergonomicamente corretos, somado a falta de conhecimento em ergonomia, faz com que estes jogadores tenham alto risco de lesão, como confirmado pelos métodos realizado na pesquisa.

Vilas acredita que os usuários de computadores estão submetidos a movimentos repetitivos, elevado esforço mental e stress. Contudo, estes fatores associados com problemas do foro oftalmológico e posturas incorretas, são capazes de originar LMERT, sigla utilizada para Lesões Músculo-Esqueléticas Relacionadas com o Trabalho (VILAS, 2016).

Para a Direção-Geral da Saúde, 2018, as LMERT podem ser caracterizadas por presença de dores, em sua maioria localizada, mas que podem irradiar para outras áreas corporais; sensação de dormência ou de "formigueiros" na área afetada ou em áreas próximas; sensação de peso; fadiga ou desconforto localizado e, também, por sensação de perda ou mesmo perda de força propriamente dita (Direção Geral Da Saúde, 2008).

Os sintomas costumam surgir de maneira gradual ou durante o pico da atividade. Nos jogos, este momento seria caracterizado pelos momentos em que as batalhas se encontram acirradas e exigem maior esforço e concentração do jogador.

Conforme a exposição aos fatores de riscos continua, os sintomas passam a ser cada vez mais persistentes, podendo até mesmo serem mantidos nos períodos de repouso e interferindo em atividades de rotina (Direção Geral Da Saúde, 2008).

Além disso, vale ressaltar que sintomas relacionados aos olhos em usurário de computador têm sido pauta de diversos estudos. Conhecida como Síndrome da Visão do Computador (CVS) e caracterizada pela fadiga ocular, cansaço visual, sensação de ardor e vermelhidão (entre outras), é um transtorno recorrente. Segundo estudo publicado em 2005, $90 \%$ dos 70 milhões de trabalhadores dos EUA usuários do computador experimentam a CVS de alguma forma (Blehm C et al., 2005).

Quanto aos fatores apenas psicossociais, acredita que estes, por si só, não são suficientes para a origem de LMERT. Entretanto, sabe-se que em partidas importantes 3 dentro dos jogos, os jogadores tendem a ficar ansiosos e isso pode ser representado a níveis somáticos, gerando tensão musculares (Brandão, 1995).

A falta de informação e de acompanhamento profissional, sobretudo de um fisioterapeuta, quanto as condições ergonômicas em que os jogadores estão inseridos, faz com que estes só procurem auxilio quando a lesão alcança um nível elevado. Por esse motivo há crescentes números de jogadores aposentados devido a lesões, como no caso no Uzi, jogador profissional afastado por acúmulo de lesões (Gama, 2020).

O jogador de LoL conhecido como Uzi, famoso por ser considerado um dos melhores atiradores dos últimos tempos, se aposentou em junho de 2020, aos 22 anos de idade. $\mathrm{O}$ astro chinês que participou de dois mundiais de LoL, deixa os campos de batalha devido a fortes dores no ombro (Gama, 2020).

Isso implica que, lesões que comprometem a saúde de um jogador, seja de forma física ou mental, podem ser agentes facilitadores de disfunções, causando interferências que vão além do desempenho, atingindo a qualidade de vida do indivíduo e até mesmo na sua personalidade. Portanto, orientações ergonômicas são fundamentais (Gentil, 2011).

Entretanto, se um indivíduo treinou a vida inteira em uma posição considerada errada, garantir o mesmo desempenho em uma posição ou mobiliário diferente pode ser um desafio. Por isso, o ideal é que o indivíduo tenha acesso a informações, auxilio profissional e se policie quanto à postura enquanto joga, fazendo os ajustes necessários até que estes se tornem espontâneos.

Para a aplicação dos princípios da ergonomia, o fisioterapeuta precisa realizar observação do local e tarefas realizadas, pois o primeiro passo para solucionar um problema é reconhecendo-o.

O fisioterapeuta é um profissional suficientemente capacitado para instruir jogadores na prática de prevenção de lesões musculoesqueléticas, realizar ajustes ergonômicos pautados no que preconiza as normas de ergonomia, incentivar a prática de adoção de hábitos saudáveis e até mesmo na reabilitação, campo que tem se mostrado cada dia mais necessário.

Infelizmente, pouco se encontra no âmbito científico sobre a fisioterapia no âmbito dos E-Sports no cenário atual. Entretanto, em entrevista para ESPN Esports Brasil, alguns fisioterapeutas atuantes da área relatam como acontece o processo de tratamento e aumento de desempenho dos jogadores.

Kenji, por exemplo, afirma que o tratamento não se difere das modalidades tradicionais, que a partir da adaptação é possível traçar um plano terapêutico singular, onde podem ser utilizados aparelhos de eletroestimulação transcutânea, acupuntura, cionesioterapia, entre outras técnicas (ESPN, 2020).

Tudo isso indica que esta é uma área em ascensão ainda para os fisioterapeutas, porém, com enorme potencial e necessidade de atuação, tendo em vista a quantidade de jogadores e os elevados riscos relacionados ao hábito de jogar. $O$ investimento na ergonomia voltada para estes jogadores é capaz de 
proporcionar melhores experiências dentro do âmbito dos jogos, bem como conforto, funcionalidade e consequentemente qualidade de vida.

\section{Conclusão}

Todos os jogadores avaliados apresentaram posturas inadequadas do ponto de vista ergonômico, o que somado a alta utilização do mouse e teclado geram um alto risco de lesão para estes. Quanto aos achados mais relevantes, destaca-se a irregularidade dos equipamentos utilizados, o que demanda ajustes para seus determinados biótipos.

Durante o uso do computador, todos apresentaram consideráveis irregularidades quanto à postura do tronco, membro superior e pescoço. Este dado mostrouse relacionar com os achados de dores relacionadas ao hábito de jogar, no qual a dor na coluna e punho tiveram prevalência entre os jogadores. Este fator mostrou ser um risco para possíveis lesões, tendo em vista que as inadequadas de suas mesas e cadeira geram uma necessidade de adaptação inadequada do corpo para exercer as tarefas.

De forma geral, os resultados demonstraram que todos os jogadores necessitam de orientações ergonômicas, tanto para ajustes de altura dos equipamentos, quanto para adequações posturais. Portanto, é necessário que haja uma desmistificação da atuação do profissional de saúde, sobretudo o fisioterapeuta, como atuante somente no tratamento de lesão, pois este também tem papel crucial na prevenção de riscos de lesões e é capaz de proporcionar melhor desempenho e qualidade de vida para estes jogadores.

No entanto, é necessário que haja mais estudos baseados em evidências, para que sejam criadas e divulgadas orientações mais precisas e, de fato, voltadas para os jogadores usurários de computador, principalmente quanto as medidas de prevenção.

\section{Agradecimentos}

Eu agradeço por todos os momentos em que os jogos me acolheram e me proporcionaram um lugar em que eu pudesse me encontrar, encontrar amigos e também aventuras. Agradeço em especial ao meu irmão por ter me apresentado e me contagiado com seu amor pelos jogos. Agradeço também ao meu orientador, Nelson Kian, por ter acreditado e me incentivado a realizar essa pesquisa, ela não teria sido possível sua enorme bagagem de conhecimentos. Aos amigos e familiares, agradeço pelo apoio que me motiva e me dá forças para propagar o bem. Sou grata por cada jogo e por cada jogador que ajudou a construir a minha história.

\section{Declaração}

$\mathrm{O}$ autor declara estar ciente e ter atendido integralmente às normas preconizadas para as pesquisas em 3 seres humanos, conforme resolução 466/2012. O autor declara ainda ausência de conflito de interesses.

\section{Referências}

Aranha, Gláucio. O processo de consolidação dos jogos eletrônicos como instrumento de comunicação e de construção de conhecimento. Ciências \& cognição 2011: 21-62.

Batista, Mônica de Lourdes Souza; QUINTÃO, Patrícia Lima; LIMA, S. M. B. Um estudo sobre a influência dos jogos eletrônicos sobre os usuários. Revista Eletrônica da Faculdade Metodista Granbery 2008: 2-11.

Blehm C; Vishnu S; Khattak A; Mitra S; Yee Rw. Computer Vision Syndrome: a review. Surv. Ophthalmol, 2005 May-Jun; 50: (3):253-62.

Brandão, Maria Regina Ferreira. Ansiedade em atletas. Movimento em medicina; 1995; 1.

Costa, Juliana Cecília Munhoz; Klein, Alison Alfred. Utilização das ferramentas moore garg e RULA pré pós melhorias no setor operacional de uma indústria de bebidas. Blucher Engineering Proceedings 2016; (3): 845-850.

Da Silva, Ana Lúcia Gonçalves; Barbosa, Ado Vilela. Computadores provocam acidentes de trabalho? In: Anais colóquio estadual de pesquisa multidisciplinar \& congresso nacional de pesquisa multidisciplinar 2017: 2527-2500.

De Souza Montes, Fillipe; Perani, Letícia. Metagame: Um possível tema para a análise de jogos competitivos. XV SBGames. São Paulo - SP, 2016: 2179-2259.

Direção Geral Da Saúde. Lesões músculo-esqueléticas relacionadas com o trabalho: guia de orientação para a prevenção; 2008.

ESPN. Fisioterapia nos esports: como o cenário está cuidando da prevenção a lesões dos jogadores. 2020. [Acesso em 21 abril 2021]. Disponível em: [www.espn.com.br/esports/artigo/_/id/6870786/fisiotera pia-nos-esports-como-o-cenario-esta-cuidando-daprevencao-a-lesoes-dos-jogadores]

Gama, Luiz Eduardo. Esportv. Astro do Lol Na China Confirma aposentadoria por problemas de saúde; jun de 2020 [acesso em 10 jun 2020]. Disponível em: https://globoesporte.globo.com.

Gentil, Rosana Maura Et Al. Síndrome da Visão do Computador. Computer Vision Syndrome. Science 2011; 2 (1): 64-6.

International Ergonomics Association. Definição internacional de ergonomia. Revista ação ergonômica 2011:1-3.

Kisner, C. \& Colby, L. A. Exercícios terapêuticos: fundamentos e técnicas. (3rd Ed.) São Paulo: Manole; 1998.

Lianza, S. Medicina de reabilitação. (3rd Ed.), Rio Janeiro: Guanabara Koogan. 2001.

MENA, F. Estudos destacam lado bom dos games, mas alertam contra excessos. 2003 [acesso em 10 jun 2020]. Disponível em: http://www1.folha.uol.com.br/folha/. 
Ministério do Emprego e da Segurança Social (Br). Estabelece as Prescrições Mínimas de Segurança e de Saúde Respeitantes ao Trabalho Com Equipamentos Dotados de Visor. Portaria N. ${ }^{\circ}$ 989/93, de 1 de outubro de 1993.

Porto, Victor Hugo. Média de salário anual na lcs é em torno de r\$1 milhão, afirma comissário da Riot. Maisesports. Lol. 24 de abr de 2019 [ acesso em 10 jun 2020]. Disponível em: https://Www.Maisesports.Com.Br/LolMedia-Salario-Lcs-Milhao/.

Ribeiro, Alexandre Cesar Machado. A indústria de vídeo games e seu impacto econômico. TCC. Mato Grosso, Cuiabá; 2015 [acesso em 10 jun 2020]. Disponível em: http://bdm.ufmt.br/handle/1/481.

Riot Games. Nossa história; 2020 [acesso em 10 jun 2020]. Disponível em: https://Www.Riotgames.Com/PtBr/Quem-Somos/Valores.

Serranheira, Florentino; Uva, António Sousa. Ler/Dort: que métodos de avaliação do risco?. Revista brasileira de saúde ocupacional 2010; (122): 314-326.

Signori, Luis Ulisses; Guimarães, Lia Buarque de Macedo; Sampedro, Renan Maximiliano Fernandes. Análise dos instrumentos utilizados para a avaliação do risco da ocorrência dos dort/ler. Produto e produção 2004; (3): 51-62.

Sobotta J. Atlas de Anatomia Humana. Volume 1. Rio de Janeiro: Guanabara Koogan. 1984.

Souza, Matheus Henrique Gomes Araujo De. O patrocínio no esporte eletrônico e sua influência sobre o consumidor. Trabalho de curso. Pampa, 2017; [acesso em 10 jun 2020]. Disponível em: http://dspace.unipampa.edu.br:8080/jspui/handle/riu/20 1.

Vilas, André Da Silva. Análise ergonómica de postos de trabalho com computadores. Tese de doutorado; 2016. 